\title{
VIDA
DE LAS PALABRAS
}

\section{Dr. Manuel Antonio Quirós}

\section{I.Introducción:}

Las lenguas son`el producto, no sólo de circunstancias lingüísticas actuales, sino también históricas; no hay lenguas sin historia. No se podría decir con exactitud cuándo es que una lengua, o conjunto de lenguas, vio la luz; las lenguas son más bien el producto de una cadena de eslabones históricos ante y postpuestos a sus estratos lingüísticos respectivos. En el caso del español y de las lenguas romances, el "sustrato" está constituido por el LATIN CLASICO-VULGAR. ${ }^{1}$ De lo anterior se deduce la validez de los estudios históricos en la lingüística, o lo que es lo mismo, la "diacronía" de las lenguas. Al hacer estos estudios en el campo románico, nos interesa el latín como punto de partida y los sustratos y superestratos de las lenguas románicas. También éstas se encuentran sometidas a un continuo flujo y reflujo, a un continuo cambio e intercambio lingüístico en los que los elementos extranjeros han jugado y juegan todavía un papel muy importante. La historia lingüística nos demuestra que los elementos extranjeros en un idioma son inevitables y que muchas veces son hasta necesarios; así pues, desde el punto de vista ${ }_{1}$ histórico-lingüístico, no existe ninguna lengua "pura" ni "nacional" en un $100 \%$. Ella es la que determina la cantidad de préstamos de sustratos y de superestratos tomados de los diferentes pueblos en relación con una lengua determinada, en el caso del español, los préstamos celtas (sustrato) o del árabe (superestrato).

Veikko Väänänen afirma: "Es en el vocabulario donde mejor se manifiesta la renovación de una lengua ... Los accidentes que modifican la economía de un vocabulario son de dos órdenes principalmente: $1^{\circ}$ cambios del fondo léxi$\mathrm{co}$, es decir, pérdidas y adquisiciones. $2^{\circ}$ renova- ción semántica, o sea, cambios de sentidoo de significado. No hace falta decir que los dos procesos pueden encontrarse combinados: una pérdida está llamando un sustituto, con riesgo de modificar el sentido.

Algunas palabras "envejecen", caen en desuso, "mueren" ... y otras mil que eran antaño de uso corriente, mientras que otras vegetan relegadas en jergas especializadas o regionales: ... No es fácil dar con la causa de las quiebras léxicas. Sin embargo, generalmente es de orden psíquico, social o étnico" 2 .

Otras palabras son sustituídas por palabras de origen extranjero, como por ej., la palabra "bellum" = guerra, sustituida por la voz germánica "werra". El estudio de estas variaciones lingüísticas en el tiempo es objeto de la gramática o lingüística histórica; estudiamos aquí las diferencias de las lenguas entre dos o más períodos de tiempo; es lo que se llama diacronía de una lengua. En este estudio diacrónico notamos (históricamente) dos tipos de palabras: las nativas y las prestadas, llamadas comúnmente "préstamos" 3 ; el estudio, tomado en forma individual para cada palabra, se llama "etimología" 4 , que, sin excluir el aspecto sincrónico, se sitúa más en el contexto diacrónico. $\mathrm{La}$ "etimología" es el estudio del origen, evolución y comparación de las palabras. Ella establece la correspondencia real o verdadera entre la cosa denominada y la designación nominal de ese mismo objeto; en otras palabras, es la correspondencia entre el "significante" y el "significado"; es pues la etimología, el conocimiento de la verdad por medio del estudio del origen y desarrollo de los vocablos; cuando se dice, por ej., "pluma de escribir", se está haciendo una relación con la "pluma de los pájaros" con que se escribía antes. 
Saussure dice que la etimología remonta el pasado de las palabras hasta dar con algo que las explica. Porque la etimología es ante todo la explicación de las palabras por la investigación de sus relaciones con otras, por lo que en lingüística, "explicar una palabra" es remitirla a otra ${ }^{5}$.

Para P. Guiraud, la etimología es el estudio de la formación de las palabras, esto es, de la cronología y relación entre la forma primitiva y su derivado morfológico (de forma) o semántico (de sentido) ${ }^{6}$. Y Walther von Wartburg: "Die Frage nach der Herkunft der Wörter nennt man im allgemeinen Etymologie" ... "Die Romanisten sehen ihre Aufgabe darin, die Wörter der romanischen Sprachen bis zum Lateinischem (evtl. zum Keltischen, Germanischen usw.) zurückzufühen Mit der Feststellung der Tatsache, dass fr. "champ" auf lt. "campus" zurückgeht ist das seiner Forschung gestellte Problem gelöst. D. h. die Romanisten betrachten einen abgeschlossenen Zeitraum von etwa 2000 Jahren"... ?

\section{Objetivos de la Etimología:}

1 - El establecimiento de la genealogía u origen de la palabra base; en el caso, por ej., de las lenguas romances, predominantemente es el latín, como arriba lo declara el romanista $\mathrm{W} . \mathrm{v}$, Wartburg. La palabra "hermano" procede del latín "germanum" que procede de "fratrem germanum", locución ésta que significa "hermano de padre y madre' en la cual "germanu" tiene su sentido propio de "habitual, verdadero, auténtico' y con la misma etimología que lat. "germen, inis" = 'germen', 'principio', 'botón', 'retoño', palabra que se puede muy bien relacionar con el verbo lat. "gignere" = engendrar. El francés y el italiano han derivado respectivamente 'frère' y 'fratello' del primer elemento de la locución latina "fratrem". Como característica fonética importante de la palabra en español es la " $h$ " inicial, introducción ortográfica inútil, según Menéndez Pidal, pues sólo la "f"- (inicial latina) es la que da "h" en español ${ }^{18}$

2 - La etimolcgía, no sólo establece el origen y la derivación inmediata, sino también, tiene por objeto dar la HISTORIA COMPLETA DE LA PALABRA, y en este sentido, busca su ayuda en la fonética, la morfología, la semántica y la comparación con otras lenguas, y desde el punto de vista cultural, en la historia, la distribución geográfica y en el comentario de textos.

3 - Por el punto anterior se puede deducir que también ella puede establecer la realidad histórica.

4 - La etimología, al indagar el origen de cada voz, constituye la historia de los idiomas y descubre la afinidad entre los mismos. Con respecto a las lenguas romances, la norma anterior tiene mucho valor. Con relación al español, a modo de ejemplo, hay un $70 \%$ de palabras (sólo palabras) provenientes del latín; muchas de ellas no parecen latinas a primera vista, pero un estudio etimológico nos aclarará muchas dudas y nos abrirá mayores perspectivas de conocimientos. La palabra 'atril' nada nos dice que tenga que ver con "legere" 'leer', cuyo supino es "lectum"; de ésta se deriva "lectorem", que a su vez da "lectorilem", de donde procede 'letril' y 'latril', voz que da directamente origen a la palabra en cuestión. Otro ejemplo: 'galgo' es una raza de perro; la palabra procede de "gallicum" =galo; "canis gallicus" = perro francés; "praecipitare" viene de "prae" y de "caput".

\section{Etimologias falsas:}

La explicación etimológica está llena de falsas interpretaciones. Tanto antiguamente como en los tiempos más recientes, el hecho de que se hayan hecho etimologías sin ningún conocimiento técnico, ha dado origen a etimologías completamente descabelladas, comenzando con los griegos, siguiendo con la Edad Media, luego con el Renacimiento y terminando casi con los finales del S. XVIII, que es cuando con el método histórico-comparativo se sientan las bases de los estudios científicos en el campo de la lingüística indoeuropea, germánica y románica; no es pues, sino a partir de los orígenes de la filología románica y de la gramática histórica, procedentes ambas del método histórico-comparativo, que el estudio de las etimologías llegó a ser "científico", esto es, metódico y verdadero. A los antiguos absurdos se ha sustituido la sistematización científica. Muchas fábulas y anécdotas nos han dejado Platón y San Isidoro de Sevilla; sólo con Grimm y Diez, fundador éste de la filología románica, se acaban esos absurdos ${ }^{9}$.

En la Edad Media es famoso San Isidoro de Sevilla por sus etimologías, tanto es así, que se ha convertido casi en el símbolo de la "mala etimología". He aquí algunas etimologías dadas por San Isidoro:

- "Lactuca dicta est quod abundantia lactis exuberet, seu quia lecte nutrientes feminas implet... lectuca agrestis est quam serraliam nominamus, quod dorsum eius inmodum serrae est.

- El gato se llama "cattus" "quia cattat, id est, videt".

- Omne satis viride, amarum dicitur.-

- Camisias vocari quod in his dorminus in camis, id est in stratis nostris - 
- Maciones dicti a machinis in quibus insistunt propter altitudinem paretum -Catenatum, quod capiendo teneat."

Algunos han dicho que 'cadáver' viene de "caro dat vermibus" (la carne da a los gusanos) o que "pantalon" en fr. viene de "pend au talon" (que cuelga del talón), que fr. 'chemise' viene de "chair mise". Históricamente, es interesante observar la etimología de una iglesia en Bélgica que se llama "Sainte Marie aux rats": Santa María de las Ratas. Parece que se construyó una iglesia con las mismas piedras de la anterior que tenía en una de sus paredes esta inscripción: "ORA PRO NOBIS". Al momento de construir la nueva iglesia, las diferentes piedras con las tres palabras mencionadas quedaron separadas y "ORA" quedó separada de las otras dos palabras; "ora" en la pronunciación francesa suena "aux rats", lo que dio el nombre a la Iglesia de Sainte Marie aux Rats. Rabelais nos ha dejado una sátira divertida de la etimología humanista: "Carymon, Caramara! par saincte marye nous son baignez par rys! (s'écrient les Parisiens sous le déluge urinal du bon géant). Dont fut dupuis la ville nommée Paris", la cual se llamaba "Leucèce", del lat. Lutetia del gr. "leuketia" de "leukós" =blanco; y Rabelais forma una etimología fantasiosa, pues dice que de "leuketía" "blanchette" viene Lutetia (París) "pour les blanches cuisses des dames du dit lieu", "por los muslos blancos de las piernas de las señoritas del mencionado lugar".

Se manipula también con el anagrama ROMA: AMOR, = Roma, sede del amor (divino), cuando en realidad "Roma" viene de "Ruma", gentilicio etrusco 10

Pero a ningún filólogo medieval se le ocurre, por ej., dẹcir que fr. "eau" viene del latín "aquam", como de hecho es así. La onomástica se prestaba mucho para hacer toda clase de derivaciones fantásticas y así poder establecer genealogías y remontarse de este modo hasta los hebreos y los griegos.

Los primeros apologistas y exégetas exageraron este tipo de conjeturas a la antigua, conjeturas que florecerán con los Padres de la Iglesia; ya se vio el caso de San Isidoro, e igualmente como él, los Padres de la Iglesia se preocupaban, para afirmar su doctrina, de darle muchas explicaciones a las cosas. Así "homo" = "humus" porque el hombre ha sido formado por Dios del "barro de la tierra": "Memento homo quia pulvis es"; se decía "crura" = piernas, porque las piernas son semejantes al Madero de la Cruz ${ }^{11}$; que "bellum" es una cosa que no es "bella" (quod res bella non sit); "foedus", alianza, por celebrarse con la matanza de un puerco (a foeditate porci) ${ }^{12}$. Así pues, la eti- mología se ha afirmado con el nacimiento de la gramática comparada del siglo XIX y con el método fono-histórico y léxico-histórico; los cambios fonéticos, regulares en límites de tiempo y espacio determinados, permiten establecer la relación entre el derivado y su "étymon" ; así, "vida" viene de "vitam", en la que se puede decir generalizando que la " $t$ " intervocálica latina da en español "d". Estas leyes parecieron universales, pero no lo son, sino que accidentes fonéticos, tales como la analogía, la contaminación, etc., producen sus efectos, pues actúan sobre el lenguaje numerosos factores que hacen dificultosa la aplicación de esas leyes universales $^{15}$. Resumiendo, según W. v. Warburg, para hacer la etimología de x palabra es necesario hacer la HISTORIA COMPLETA DE ESA PALABRA. La etimología es la historia completa de la palabra; en el caso de cualquier lengua romance, desde el latín, pasando por los intermediarios, con posibles fechas, cambios de sentido, alteraciones fonéticas atestadas o reconstruídas. De este modo, se cumple la tarea de: a) averiguar el origen primero, b) de establecer la relación entre 2 palabras, un étymon $\mathrm{E}$ inmediato con su derivado D; entre E y D existen relaciones de similitud, continuidad, causa-efecto, etc.; la derivación, a su vez, está condicionada por la cronología, el espacio, los cambios internos, las vías de transmisión, las necesidades de los interlocutores y el cambio mismo. Las circunstancias históricas en las cuales las palabras nacen, juegan un papel preponderante para explicar su origen. Toda palabra en sus inicios está motivada y presenta cierta relación con la cosa nombrada. La palabra está motivada por la cosa misma. A partir de este postulado fue que se creó en Alemania en 1909 el movimiento "Wörter und Sachen" 'Palabras y Cosas' por Rudolf Meringer. El método pone de manifiesto el acento sobre la prioridad de la cosa sobre la palabra, pues la palabra viene con el objeto o la "Sache", (la cosa). Es natural que tenga que existir una relación entre el nombre y el cómo se llama esa cosa,como por'ej: cuando se dice en fr. "fleuve" 'río' del verbo latino "fluere" 'correr'; río es el que fluye, el que corre, o como cuando se dice en español 'pensamiento' de "pensum" que viene de "pensare" y el cual debe ser relacionado con "pendere" 'pesar', pues el pensamiento es lo pensado, id. est, lo ponderado, lo pesado.

\section{Algunas Etimologias:}

Albañil: $\quad$ 1268. Del árabe vulgar 'banní', pronunciación hispana del cl. al-bannâ = constructor. En francés la palabra correspondiente "macon" proviene del francón 
"makjo" cuya palabra ya se encuentra en las Glosas de Reichenau del siglo VIII: Caementariis: macionibus. En italiano la palabra procede del lat. "muru" = pared; en prov. de "petrarium" que da 'paire', en catalán es 'paleta' (del albañil) en portugués es 'pedreiro' y 'alvannel'. El rum. tiene una voz de origen eslava "zidar" procedente de 'zid' = muro.

Ajedrez: h. 1250. Del ár. sitránŷ y ésta del sánscrito catur-anga 'el de cuatro cuerpos', aludiendo a las 4 armas del ejército índico: infantería, caballería, elefantes y carros de combate - simbolizados respectivamente por los peones, caballos, alfiles y torres. En esp. ant. es 'axedreç' y en portugués es 'xadrez'.

Azar: En esp. ant. = cara desfavorable del dado; luego, lance desfavorable en el juego de los dados; en 1281, cierto juego que se jugaba con los dados; en 1250 es ya el sentido moderno: 'mala suerte, desgracia, suerte, riesgo'; a mediados del XVI: 'casualidad, caso fortuito'. La palabra viene del ár. "azahr" = "flor, vulgarmente, "dado", por la flor que se pintaba en una de sus caras'. De España la voz pasó a Francia como 'hasard', del fr. viene el italiano 'azzardo'.

Carnaval: 1495, raro hasta el siglo XVII. Del it. 'carnevale' y éste procede de "carnelevale", 1130, alteración de "carnelevare"; es un compuesto de "carnem" y del verbo "levare" (que es el que da en esp. llevar); llevarse o quitar la carne por ser el comienzo del ayuno cuaresmal. Según Corominas, el nombre tradicional en castellano es 'carnestolendas' del verbo "tollere" inf. de "fero", "tuli" = "llevar".

Cero: h. 1600. Tomado del it. 'zero', S. XV que a su vez lo tomó de la forma árabe latinizada "zephyrum" y éste del ar. "sifr", que al principio significaba 'vacío', según Tagliavini, merced a un calco del sánscr. "śunyá = 'vacío', pero que los matemáticos indios emplearon para 'cero'; el ar. sifr. adquirió entre los matemáticos el mismo sentido de 'cero'. Leonardo Fibonacci latinizó el término 'zephirum' que luego en las fuentes italianas, se volvió 'zefiro, zefro, zero' (1491); de él procede el fr. 'zéro' y el esp. 'cero'. Una adaptación de la palabra árabe más próxima al original es la del español 'cifra' e it. 'cifra' con el valor de 'signo numérico'.

"Sifr" se aplicó en romance primeramente al cero y después a los demás guarismos.

Compañero: En el caso de esta palabra nos en- contramos ante una traducción parcial o calco; id est, una palabra de cuerpo latino con significación germánica. Proviene de 'cum' más 'panionem' que a su vez viene de 'cum' más 'pane'; literalmente 'compañero' significa el que comparta el pan con uno; este significado es propio del latín medieval y procede del germánico,"ga" = 'cum' y del sust. "hlaiba" que procede de "hlaifs" = pan. La palabra compañero sustituyó a la latina 'come', 'itis' de la cual se deriva 'conde'.

De bruces: No se está seguro del origen exacto de esta locución: 1) ¿viene del ar. bus= beso? - 2) ¿es un cruce con el vasco 'buruz' = cabeza? - 3) Corominas dice que es de origen incierto, pero agrega que quizá sea una variante de 'bozo' = parte inferior del rostro - 4) caer de bruces significa caer con la cara hacia la tierra, lo que implicaría la idea del regreso y podría derivarse del latín 'avorsus' - 5) Lapesa dice que la locución viene del vasco 'buruz' cruzada con el árabe.

Hallar: Las palabras del latín cl. "invenire", compuesta de la prep. "in" y el verbo "venire", usada más en el habla corriente, $y$ el verbo "reperire" usado en el estilo más elevado, fueron sustituidos en el latín vulgar por el verbo tomado del lenguaje de la caza "afflare" de "adflare" = 'soplar', 'rozar algo con la nariz' (que es exactamente lo que hace el perro antes de comerse algo o al ir en busca de la presa; de aquí, oler la pista de algo y luego encontrar). En francés, provenzal, calatán e italiano parece que los verbos respectivos proceden del latín vulgar "tropare" y éste del gr. "tropos" = 'figuras de dicción'. En la primera lengua la palabra es "trouver", en las dos siguientes es 'trobar' y en italiano es 'trovare'. El prov. 'trobar' ha tenido una amplísima dịfusión, pues de ahí se deriva 'trobador', el poeta del amor cortés por excelencia. Según Corominas. la forma antigua de "fallar", en el sentido de 'encontrar la ley aplicable' y en el de 'encontrar o averiguar los hechos' pasó a significar 'dar sentencia', S. XIV. Pues el lenguaje jurídico es tradicional y arcaizante y por eso conservó una forma no tan evolucionada.

Hidalgo: Forma reducida de 'hijo de algo'. Al respecto, Lapesa dice lo siguiente: "es un arabismo semántico". El árabe llama "hijo de una cosa' a quien se beneficia de ella (el rico es 'ibn addunya') hijo de la riqueza; el ladrón es 'ibn al-layl' =hijo de la noche', porque la noche favorece el robo; 
así se explica el primer elemento de "hijodalgo' que da 'hidalgo', voz sinónima del 'hijo de bienes'. En este caso, la palabra es románica en cuanto al origen: "filiu" más "aliquod" y en la evolución formal de su significante, pero parcial o totalmente arabizada en su contenido significativo, pues ha adquirido una acepción nueva por la presencia mental de una palabra árabe con la que tenía algún significado común.

Higado: En las glosas de Reichenau del S. VII encontramos: Iecore: ficato. En lat. cl. se decía hígado "iecur, iecoris"; voz que no es románica. La palabra 'iecur' fue del todo sustituida en todas las lenguas romances debido a una receta tomada de los griegos. Estos tenían la costumbre de engordar gansos con higos (lat. ficos) para obtener de ese modo un 'higado sabroso' llamado en gr. sykotón . Los latinos calcaron esta forma con la palabra correspondiente "fícatum"; la cual, con diferente variedad en el acento, fue la que dio la palabra 'hígado' en esp., en port. 'fígado', fr. 'foie', prov. 'fege', it. 'fegato', rum. 'ficat' y cat. 'fetge'. La receta se debe a M. Apicio. El calco griego está documentado desde el s. IV. La forma francesa 'foie' (ant. fr. 'fege' o 'feie') es el resultado de una metátesis del mismo latín vulgar: "ficatum" da "fíticum". La forma griega es 'hépar sykotón' que da en latín 'iecur ficátum'.

Llegar: Para este verbo el latín cl. poseía el término 'ad-venire', término que llegó a desaparecer por adquirir el sentido figurado de 'suceder, pasar, acaecer': (advenit periculum, dies advenit). Quizá la difusión temporal hizo que se diera preferencia a otros verbos para expresar la difusión local. Entre ellos, el que tuvo másfortuna fue "plicare" verbo que dio origen a un doblete etimológico: por un lado, el semi- cultismo 'plegar', 'doblar' y por el otro, la voz popular 'llegar' con el cambio del grupo pl-a 11-. El valor de "plicare" en el sentido de 'doblar' fue tomado de la terminología marítima; dado que "plicare vela" significa 'plegar las velas', pues ya se está llegando al puerto; lo contrario del rumano, en el que el significado está tomado del sermo castrensis: "plicare tentoria" es 'doblar las tiendas para irse', de donde "plec la Bucuresti" significa 'parto hacia Bucarest'.

En la "Peregrinatio Astheriae" ya se encuentra "plicare" con el sentido de "llegar': "plicavimus nos ad mare" "cum iam prope plicarent civitati" "ut plecaremus nos ad montem". Según G. Rohlfs, fue debida a la autora de la Peregrinatio la fortuna de "plicare" en la Península Ibérica. En francés existe otro sustituto de "advenire"; es "adripare" que viene de "ripam': 'arriver', el cual da en prov. 'arribar' y en it. 'arrivare'. En español esta palabra, con el significado de expresión náutica, no es galicismo: arribado an lás naves, fuera eran exidos (Cid: V. 1629.) "et vido arribar una nave" (Calila).

Mengano y sutano: Del indefinido árabe 'fulán' = uno, cualquiera, procede fulano, y de "man kana", procede 'mengano'. Son estos unos de los pocos casos de adjetivos árabes sobrevivientes en españo. Otros adjetivos son: garrido, mezquino, baladí y baldío.

Tocayo: Probablemente empezaron a llamarse 'tocayo' y 'tocaya' las parejas que llevaban un mismo nombre, por alusión a la frase ritual del Derecho Romano: "Ubi tu Caius, ibi ego Caia" (donde tú seas llamado Cayo, a mí me llamarán Caya) que la esposa dirigía al novio al llegar a su casa la comitiva nupcial. 
No hay que exagerar la oposición "latín clásico-latín vulgar"; ambos son cauces de un mismo río. La oposición debe ser solo de tipo metodológico.

Veikko Väänänen, Introducción al Latín Vulgar, ed. Gredos, Madrid, 1971, pág. 127, No. 138 y 139 .

El término comúnmente empleado es la palabra alemana "Lehnwort" - préstamo.

La palabra viene del griego "étymos" verdadero.

Ferdinand de Saussure, Curso de Lingüistica General, ed. Losada S.A. Buenos Aires, 1973.

Pierre Guiraud, L'Etymologie, ed. Pr. 11 Universitaires de France, París, 1967, pág. 6.

"Se llama etimología a la respuesta de la pregunta sobre la procedencia de las palabras"... "Los romanistas cumplen con su tarea al remontar las apalabras de las lenguas romances hasta el latín (event. hasta el celta, el germánico, etc.) Con la comprobación de que el fr. "champ" procede de lat. "campus", ya queda solucionado el problema para su averiguación. Esto quie:e decir que los romanistas tienen un período histórico de casi 2000 años"...
Walther von Wartburg, Eifübrung in Problemat$i k$ und Methodik der Sprackwissenschaft, Max Niemeyer Verlag, Túbingen, 1962, pág. 114; trad. del autor de este artículo.

El ejemplo está tomado de J. Corominas, Breve Diccionario etimológico de la Lengua Castellana, ed. Gredos, Madrid, 1967.

Platón dice que Dionisio viene de "didoùs tón oînon 'el que da el vino'

10

Rumon es un antiguo nombre del Tíber; de "Rumon" se derivan Romulus y Remus de la leyenda, según Carlo Tagliavini, Le origini delle Iinque Neolatine, Patrón, Bologna, 1964, nota 4 de la pág. 58.

Se confundió ",cruz, crucis" - la cruz con "crus cruris" - la pierna

12 bellum, i, n. - la guerra y bellus, a, um - bello, un adj. competidor de pulcher, a, un y de formosus, a, um. Parece que "bellus" fue la causante de la desaparición de "bellum" y en su lugar entró el germánico "werra".

13 Casi todos los ejemplos anteriores han sido tomados de Pierre Guiraud, L'Etymologie, págs. 12 a 24.

\section{BIBLIOGRAFIA}

1. Block et Warttburg Walther von, Dictionnaire Etumologique de la Langue FRançaise. Ed presses Universitaires de France, Paris, 1964.

2. Brunot F. Y BRUNEAU C., Grammaire Historique de la Langue Française, Ed. Masson et Cie., Paris, 1969.

3. COROMINAS JOAN., Breve Diccionario Etimológico de la Lengua Castellana, Ed. Gredos, Madrid, 1967.

4. GUIRAUD PIERRE, L'ETYMOLOGIE, Ed. Presses Universitaires de France, Paris, 1967.

5. LAPESA RAFAEL, Historia de la Lengua Española, Ed. Escelider, Madrid, 1962.

6. ROHLFS GERHARD, Diferenciación Léxica de las
Lenguas Románicas, Ed. del CSISC, Madrid, 1960.

8. ROHLFS gerhard, Vom Vulgärlatein zum Altfranzösischen, Ed. Max Niemeyer, Tübingen, 1963.

8. SAUSSURE FERDINAND, Curso de Lingüsística General, Ed. Losada, S. A. Buenos Aires, 1973.

9. TAGLIAVINI CARLOS, Le Origini delle Lingue Neolatine, Ed. Patròn, Bologna 1964.

10. VAANANEM VEIKKO, Introducción al Latín Vilgar, Ed. Gredos, Madrid, 1971.

11. WARTBURG WALTHER VON Eifbrung in Problematik und Methodik der Spracbwissenschaft, Ed. Max Niemeyer Verlag, Tübingen, 1962. 